\title{
Clustering and Mobility of Voltage-dependent Sodium Channels during Myelination
}

\author{
Eun-hye Joe and Kimon J. Angelides \\ Departments of Cell Biology and Neuroscience, Baylor College of Medicine, Houston, Texas 77030
}

In myelinated axons, voltage-dependent sodium channels are segregated at high density at nodes of Ranvier (Rosenbluth, 1976; Waxman and Quick, 1978; Black et al., 1990; Elmer et al., 1990), a distribution that is critical for the saltatory conduction of action potentials (Huxley and Stampfli, 1949). The factors that specifically control the organization and immobilization of sodium channels at nodes are unknown. Recently we have reported that segregation of sodium channels on axons is highly dependent on interactions with active Schwann cells and that continuing axon-glial interactions are necessary to maintain sodium channel distribution during differentiation of myelinated nerve (Joe and Angelides, 1992). The specific recruitment of sodium channels at these early stages of myelination and the conspicuous absence of other axon membrane components suggest that the factors governing sodium channel cluster formation show molecular specificity. However, it is not clear whether these clustered sodium channels originate from a redistribution of preexisting diffusely distributed sodium channels. To determine how Schwann cells might regulate sodium channel distribution during myelination we have examined the lateral mobility of fluorescently labeled sodium channels at defined stages of myelination by fluorescence photobleach recovery using tetramethylrhodamine (TmRhd)-labeled Tityus $\gamma$, a sodium channel-specific fluorescent toxin. First, to test whether Schwann cells, in addition to modulating sodium channel distribution, affect the mobility of sodium channels, we cultured dorsal root ganglion neurons in the presence or absence of Schwann cells and monitored sodium channel mobility on cell bodies, axon hillocks, and axons. Even in the absence of Schwann cells, $\sim 80 \%$ of the sodium channels were immobile on the time scale of the fluorescence photobleach recovery measurement $\left(D_{L} \leq 10^{-12}\right.$ $\mathrm{cm}^{2} / \mathrm{sec}$ ), although the remaining fraction of channels are mobile with diffusion coefficients of $5-13 \times 10^{-11} \mathrm{~cm}^{2} / \mathrm{sec}$. Most importantly, in contrast to the effects of Schwann cells on altering the distribution of sodium channels, we found that Schwann cells did not alter the rate of lateral mobility or the mobile fraction of axonal sodium channels. Therefore, although sodium channel distribution depends on Schwann

\footnotetext{
Received July 2, 1992; revised Jan. 27, 1993; accepted Jan. 28, 1993

This study was supported by research grants to K.J.A. from the National Institutes of Health (NS28072), the National Multiple Sclerosis Society, the Muscular Dystrophy Association, and a Research Career Development Award (NS K04 01218 ). We thank Dr. Barry Hicks for his critical comments and helpful suggestions and Nancy David for help in preparation of the manuscript.

Correspondence should be addressed to Kimon J. Angelides at the above address.

Copyright (c) 1993 Society for Neuroscience $0270-6474 / 93 / 132993-13 \$ 05.00 / 0$
}

cell contact, immobilization of sodium channels is independent of Schwann cell contact. These effects appear to be specific for sodium channels because $45 \%$ of the succinyl concanavalin-A receptors on the axon are mobile, a fraction that decreases to $25 \%$ in the presence of Schwann cells later in development. To determine how sodium channels might be immobilized other than by Schwann cell contact, TmRhd-Tityus $\gamma$-labeled dorsal root neurons were treated with $0.5 \%$ Triton $X-100$. Under these conditions, $17 \%$ and $22 \%$ of sodium channels were extracted from cell bodies and axons, respectively, suggesting that the immobile sodium channels are linked to the cytoskeleton. Consideration of several mechanisms shows that the results are consistent with the possibility that sodium channel clusters arise by the lateral diffusion and trapping or selective exclusion of the small mobile and homogeneously distributed population of sodium channels and/or by localized insertion of newly synthesized channels that preferentially appear on the axon at sites of Schwann cell contact. These changes in sodium channel distribution are subsequently stabilized and maintained by interactions with the subaxolemmal cytoskeleton.

[Key words: sodium channel, myelin, lateral mobility, cytoskeletonl

In myelinated nerve, voltage-dependent sodium channels ( $\mathrm{NaChs}$ ) mediate generation of the action potential by a rapid increase in $\mathrm{Na}^{+}$permeability and saltatory propagation of the action potential along the axon (Huxley and Stampfli, 1949, 1951; Hodgkin and Huxley, 1952). Both electrophysiological and freeze-fracture studies have shown that in myelinated nerve the axon membrane is heterogeneous in its distribution of $\mathrm{NaChs}$, with a density of $\sim 1300 / \mu \mathrm{m}^{2}$ at nodes and less than $\sim 100 / \mu \mathrm{m}^{2}$ at internodes (Rosenbluth, 1976; Ritchie and Rogart, 1977; Kristol et al., 1978).

Some studies indicate that the structural heterogeneity of developing axons is detectable prior to the formation of mature myelin, and that the differentiation of the axon membrane into nodal and internodal regions occurs as an early event in development (Waxman and Foster, 1980; Wiley-Livingston and Ellisman, 1980). Obviously, the laying down of the myelin membrane profoundly changes the conduction properties of the axon membrane (Smith et al., 1982), but there is much less information on how glial cells in early development might specify $\mathrm{NaCh}$ distribution on the axon. The extent to which development and maintenance of the node depend upon glial cell contact has remained an important issue in neurobiology and there has been considerable debate as to what role glial cells play in organizing components of the myelinated axon, although two possibilities have been proposed. Freeze fracture and cytochemical 
stains specific for excitable membrane components have suggested that glial cell contact is nccessary for the segregation of NaChs at nodes (Rosenbluth, 1979, 1988; Black et al., 1985; Bigbee and Foster, 1989). For example, in hypomyelinating murine mutants, regions resembling nodal specializations were not observed in freeze-fracture replicas (Schnapp et al., 1976; Rosenbluth, 1979; Rosenbluth and Blakemore, 1984). On the other hand, other studies using similar murine mutants have suggested that $\mathrm{NaCh}$ specializations develop independently of glial cell contact (Ellisman, 1979).

Recent work from this laboratory has shown that segregation of NaChs on axons is highly dependent on interactions with Schwann cells (SCs), and that continuing axon-glial interactions are necessary to organize and maintain $\mathrm{NaCh}$ distribution during differentiation of the myelinated axon (Joe and Angelides, 1992). The clustering of NaChs by SC's is not a feature of all axonal membrane glycoproteins because concanavalin-A (ConA) receptors and the neural cell adhesion molecule (NCAM) are not clustered. In addition, the formation of $\mathrm{NaCh}$ clusters appears to require a specific component of metabolically active SCs because neither latex beads nor membranes prepared from SCs induce channel clustering.

In polarized cells, morphogenesis of the polarized distribution of membrane proteins is determined in part by modulating the lateral mobility and preventing free diffusion of proteins in the membrane (Tsuji and Ohnishi, 1986; Cowan et al., 1987; Myles et al., 1987; Poo and Young, 1990). During differentiation of the myelinated nerve several factors could contribute to the compartmentalization of $\mathrm{NaChs}$ on the axon membrane. One possibility is that direct linkage of $\mathrm{NaChs}$ to the axonal cytoskeleton controls and limits free diffusion of $\mathrm{NaChs,} \mathrm{similar} \mathrm{to}$ the linkage between band 3 and ankyrin in erythrocytes (Nigg and Cherry, 1980; Tsuji and Ohnishi, 1986). Indeed, there is cvidence from previous studics that shows that $\mathrm{NaChs}$ are linked to the spectrin-based cytoskeleton via ankyrin (Srinivasan et al., 1988), and that this linkage could limit the mobility of NaChs in axon membranes (Wood and Angelides, 1989). Furthermore, immunolight and electron microscopy has shown that in fully myelinated axons, ankyrin is localized at nodes of Ranvier (Kordeli et al., 1990). Alternatively, during development a physical barrier could be established in specific regions of the axon by the subaxolemmal cytoskeletal meshwork, by tightly packed integral membrane proteins, and/or by intimate contact established between the axon and $\mathrm{SC}$. NaChs could move freely within the barrier but may not be able to move outside of it. Examples of such compartmental barriers are the $\mathrm{PH}-20$ protein distributed and maintained to the posterior head region of guinea pig sperm cells (Cowan et al., 1987; Myles et al., 1987) and apical or basolateral membrane proteins that are confined to the apical and basolateral membrancs, respectively, by tight junctions of epithelial cells (Diamond, 1977). Recently it has been shown that hippocampal neurons may segregate lipids between compartments by a functional barrier (Kobayashi et al., 1992). A third possibility is that cell-cell contact between closely apposing axon and SC membranes and interactions with components of SC adhesion molecules and/or the extracellular matrix could provide a mechanism to immobilize NaChs (Chow and Poo, 1982).

To understand the cellular mechanisms and factors that differentiate the myelinated axon and how NaCh clusters accumulate and are maintained on axons, in this study we have asked whether the interaction of SCs with axons impose con- straints on $\mathrm{NaCh}$ mobility and in this way contribute to $\mathrm{NaCh}$ distribution. To do this, we have measured the lateral mobility of NaChs by fluorescence photobleach recovery (FPR) in cultured dorsal root ganglia (DRGs) in the presence and absence of SCs using a fluorescently labeled $\mathrm{NaCh}$-specific toxin, Tityus serrulatus toxin $\gamma$ (Tityus $\gamma$ ). The results reveal that even in the absence of SCs most $\mathrm{NaChs}$ are immobile, although a small population of $\mathrm{NaChs}(20 \%)$ are mobile with diffusion coefficients of $\sim 10^{-10} \mathrm{~cm}^{2} / \mathrm{sec}$. At all developmental stages the mobility appears independent of SCs. We suggest that lateral diffusion of a small population of mobile $\mathrm{NaChs}$ toward a local trap provided by SCs is a possible mechanism for the segregation of $\mathrm{NaChs}$ mediated by SCs and that SC contact provides either specific and high-affinity sites to $\mathrm{NaChs}$ or a selective barrier to $\mathrm{NaCh}$ movement but not to other axonal membrane proteins. Alternatively, we have considered that newly synthesized $\mathrm{NaChs}$ may be inserted and immobilized at specific contact sites, a distribution that is maintained later by association with the cytoskeleton.

\section{Materials and Methods}

Materials. Minimal essential medium (MEM) was purchased from GIB$\mathrm{CO}$; collagen, from Biomedical Technology, dispase and NGF, from Collaborative Research; fetal bovine serum from Hyclone; rhodamineconjugated succinyl concanavalin-A (sConA) from Vector; $\mathrm{Na}^{125} \mathrm{I}$, from Amersham; and tetramethyl rhodamine succinimidyl diester (TmRhd), from Molecular Probes. Fluorescein-conjugated goat anti-rabbit immunoglobulin antibody was obtained from Kirkegaard and Perry. All other reagents were from Sigma. The NCAM antibody was the generous gift of Dr. Karl Pfenninger of the University of Colorado School of Medicine, and the Thy 1.1 antibody was from Dr. Kay Ficlds, Albert Einstein College of Medicine. Tityus toxin $\gamma$ was a kind gift from Dr. L. Possani of the National University of Mexico.

Cell culture. Dorsal root ganglion (DRG) neurons and SCs were prepared from day 15 embryos of Sprague-Dawley rats following the procedure of Eldridge et al. (1987) with several modifications. DRGs were removed, digested with $50 \mathrm{U} / \mathrm{ml}$ of dispase, and triturated. Dissociated cells were plated on collagen/poly-D-lysine-coated \#1 glass coverslips in plating media (MEM containing $23 \mathrm{~mm}$ HEPES, $5 \mathrm{gm} /$ liter glucose, $2.2 \mathrm{gm} /$ liter sodium bicarbonate, $10 \%$ fetal bovine serum, and $50 \mathrm{ng}$ $\mathrm{ml}$ NGF).

For coculture of DRGs/SCs, plating media was changed into defined media [MEM containing $25 \mathrm{~mm}$ HEPES, $5 \mathrm{gm} /$ liter glucose, Bottenstein's N2 supplements (Bottenstein and Sato, 1979), and $50 \mathrm{ng} / \mathrm{ml}$ of NGF] within 16-24 hr. Cultures were kept continuously in defined media. Pure cultures of DRGs were prepared by growing cells in plating media and pulse treating three times with $10 \mu \mathrm{M}$ 5-fluoro- $2^{\prime}$-deoxyuridine and $10 \mu_{\mathrm{m}}$ uridine for $1 \mathrm{~d}$ at days 1,4 , and 7 from plating.

Immunocytochemistry. The distribution of $\mathrm{NaChs}$ and glycoproteins on these neuron-SC cocultures was examined. One-week-old cocultures or pure DKGs were fixed with $95 \%$ ethanol $/ 5 \%$ acetic acid for $30 \mathrm{~min}$ at $-20^{\circ} \mathrm{C}$, washed with PBS several times, and then incubated with $10 \%$ goat serum for $10 \mathrm{~min}$. Cells were then incubated with a 1:40 dilution of mouse monoclonal Thy 1.1 antibody (Fields et al., 1978) and a 1:100 dilution of polyclonal $\mathrm{NaCh}$-specific antibody 7493 (Elmer et al., 1990), overnight at room temperature. Thy 1.1 was visualized with fluoresceinconjugated goat anti-mouse secondary antibody and $\mathrm{NaCh}$ were visualized with tetramethylrhodamine-conjugated goat secondary antirabbit antibody. For NCAM staining, fixed cells were incubated with a 1:200 dilution of monoclonal NCAM antibody and visualized with fluorescein-conjugated goat anti-mouse antibodies. For the analysis of images to calculate $\mathrm{NaCh}$ intensity on axons, cells were double labeled with 7493 and monoclonal ankyrin antibody, and then visualized with rhodamine-conjugated anti-rabbit antibodies and fluorescein-conjugated anti-mouse antibodies, respectively.

Preparation and characterization of $\mathrm{NaCh}$-specific fluorescent toxin probe. Tityus toxin $\gamma$ is a 62 amino acid NaCh-specific polypeptide toxin that has six lysine residues (Barhanin et al., 1982). Tityus toxin $\gamma$ was labeled with tetramethylrhodamine succinimidyl ester (TmRhd) using methods described previously (Angelides and Nutter, 1983). Reaction mixtures included Tityus $\gamma$ and TmRhd at 1:1 mole : mole ratio 
in order to minimize modification of the multiple lysine residues. Briefly, $100 \mu \mathrm{g}$ of Tityus $\gamma(13.7 \mathrm{nmol})$ was incubated with $7.2 \mu \mathrm{g}$ of TmRhd (13.7 $\mathrm{nmol}$ ) in $50 \mu \mathrm{l}$ of $0.1 \mathrm{M}$ sodium bicarbonate buffer, $\mathrm{pH} 8.5$. After $30 \mathrm{~min}$ at room temperature, the reaction was stopped by the addition of $10 \mu \mathrm{l}$ of $1 \mathrm{M}$ glycine. The labeled toxin was purified using a $\mathrm{C}_{18}$ reversephase HPLC column eluted with a gradient from $0.1 \%$ ammonium acetate in water to $0.1 \%$ trifluoroacetic acid in acetonitrile. The optical density of the eluent was monitored at $280 \mathrm{~nm}$. The retention time of native toxin was $46 \mathrm{~min}$ and fluorescently derivatized toxins eluted at 47-62 $\mathrm{min}$. These peaks were collected from HPLC and dried under vacuum using a speed-vac (Beckman). Fractions were reconstituted with $50 \mu \mathrm{l}$ of distilled water and then tested for their ability to compete with the ${ }^{125}$ I-Tityus $\gamma \mathrm{NaCh}$ binding site on rat brain synaptic membranes (Barhanin et al., 1982)

Thirty micrograms of rat brain synaptosomal membranes were incubated on ice with $1.8 \mu \mathrm{M}$ of native toxin or varying concentrations of TmRhd-labeled toxins from HPLC fractions in a total volume of 200 $\mu \mathrm{l}$ of binding buffer ( $20 \mathrm{~mm}$ Tris, $\mathrm{pH} \mathrm{7.4,40} \mathrm{mM} \mathrm{choline} \mathrm{chloride,} 5.4$ $\mathrm{mm} \mathrm{KCl}, 2.8 \mathrm{~mm} \mathrm{CaCl}_{2}, 1.3 \mathrm{~mm} \mathrm{MgSO}_{4}, 0.1 \% \mathrm{BSA}$ ) for $30 \mathrm{~min}$. Then $4 \mathrm{nM}$ of ${ }^{125}$ I-Tityus $\gamma$ was added for $30 \mathrm{~min}$. Bound toxin was separated from free toxin by rapid filtration on GF/B filters. After washing filters twice with $3 \mathrm{ml}$ of ice-cold binding buffer, ${ }^{125} \mathrm{I}$-toxin remaining on the filter was measured by gamma counting. Fractions that competed for ${ }^{125}$ I-toxin binding as did the native toxin were pooled and used for lateral mobility experiments.

Fluorescence photobleach recovery measurements. Cells were prewashed with phenol red-free MEM containing $9 \mathrm{gm} /$ liter glucose and $2.2 \mathrm{gm} /$ liter sodium bicarbonate for $30 \mathrm{~min}$ at $37^{\circ} \mathrm{C}$. Cells were labeled with $4 \mathrm{nM}$ TmRhd-Tityus $\gamma$ for $20 \mathrm{~min}$ and washed twice with phenol red-free MEM for $5 \mathrm{~min}$ each at $37^{\circ} \mathrm{C}$. Control $\Gamma P R$ and imaging experiments were performed by first labeling cells with $1 \mu \mathrm{M}$ unlabeled Tityus $\gamma$ toxin followed by 4 nM TmRhd-Tityus $\gamma$ toxin. The nonspecific labeling based upon photon counts obtained under identical optical conditions was $<10 \%$ of the experimental. Measurement of Schwann cells (bodies) showed that labeling of Schwann cells was also $<10 \%$ of the fluorescence measured from DRG cell bodies or axons.

Lateral diffusion coefficients $\left(D_{L}\right)$ and mobile fractions $(f)$ of labeled $\mathrm{NaChs}$ were measured by the spot photobleaching technique using a Zeiss Universal fluorescence microscope and a $63 \times, 1.2$ NA water immersion lens placed directly into the culture dish (Angelides et al., 1988). The monitoring argon-ion laser $(515 \mathrm{~nm}, 5 \mu \mathrm{W})$ was focused through the microscope to a Gaussian radius of $0.45 \mu \mathrm{m}$. The illuminated region was bleached by a $50-200 \mathrm{msec}$ laser pulse $(5 \mu \mathrm{W})$, bleaching $\sim 70 \%$ of the fluorescence. The time course of the fluorescence recovery was followed with the attenuated monitoring beam. The lateral diffusion coefficient and mobile fraction were determined by curvefitting procedures (Axelrod, 1983) that weight the initial phase of the recovery curve. Diffusion coefficients, $D_{L}$ (in $\mathrm{cm}^{2} / \mathrm{sec}$ ), were obtained from $D_{L}=\omega^{2} / 4 T_{D}$, in which $\omega$ is the $e^{-2}$ radius of the beam profile and $T_{D}$ is the half-time for recovery. The lateral mobility of glycoproteins was measured as above after labeling cells with $30 \mu \mathrm{g} / \mathrm{ml}$ of rhodamineconjugated sConA. In a small area such as an axon, measurement of $D_{L}$ and $f$ are underestimated by approximately $15 \%$ (Angelides et al., 1988). Data were analyzed by a Student's $t$ test to distinguish the mean value of $D_{l}$ or $f$ and the significance of these values in the absence or presence of SCs (Zar, 1984). The standard mean errors are the result of repeated measurements on these cultures. Because there are slight variations in mobilities of fluorescent probes in FPR experiments, due to cell-to-cell variations, a large number of measurements using at least six different culture preparations corresponding to each developmental stage are used in statistical analysis to evaluate differences between developmental stages. The standard mean and deviations were derived from each group and reflect repeated measurements rather than errors in the reliability of the fit. A Student's $t$ test was used to evaluate differences between developmental groups. In some experiments, $\mathrm{NaCh}$ mobility was measured in the presence of $5 \mu \mathrm{g} / \mathrm{ml}$ colchicine or $5 \mu \mathrm{g} /$ $\mathrm{ml}$ cytochalasin $\mathrm{B}$ to disrupt microtubules and actin filaments, respectively (Angelides et al., 1988).

Digital fluorescence imaging. DRG and DRG-SC cocultures stained with antibodies were examined through a $63 \times, 1.3 \mathrm{NA}$ oil immersion objective on a Zeiss Axiovert microscope and images were captured in digital format through a $514 \times 514$ CCD camera interfaced to a Perceptics image processor. All images were captured within the linear range of the CCD camera with no saturation of the pixels. Images were processed and the integrated fluorescence intensities were calculated within the same image to facilitate comparison of the relative densities. To compare $\mathrm{NaCh}$ intensity on axons with or without clusters, the intensity of each pixel was obtained by following a length of the axon mcmbrane $(\sim 14 \mu \mathrm{m})$ in noncontact regions (i.e., nonclustered), on regions of axons between clusters (i.e., $14 \mu \mathrm{m}$ ), and at clusters. The intensity of ankyrin that is homogeneously distributed served as an internal control. Background fluorescence intensity was taken at adjacent cell-free regions and subtracted from each of these readings to yield the corrected average fluorescence intensity

Extraction of soluble sodium channels. To determine whether $\mathrm{NaChs}$ are associated with the cytoskeleton, soluble membrane proteins were extracted using the method described by Stya and Axelrod (1983) with minor modifications. One-week-old pure DRGs were labeled with TmRhd-Tityus $\gamma$ and the photon counts ( $50 \mathrm{msec}$ dwell time) in a 0.45 $\mu \mathrm{m}$ spot, using the monitoring beam of the laser, were measured on the cell body, axon, and axon hillock. The same cells were then treated with $0.5 \%$ Triton X-100 in cytoskclctal protein stabilizing buffer $(60 \mathrm{~mm}$ PIPES, $25 \mathrm{~mm}$ HEPES, $10 \mathrm{~mm}$ EGTA, and $2 \mathrm{~mm} \mathrm{MgCl}_{2}$, pH 7.5) (Marsh and Letourneau, 1984) for $3 \mathrm{~min}$ and washed twice with the same buffer. Photon counts were remeasured in these regions under identical optical conditions and then directly compared.

\section{Results}

\section{Characteristics of sensory neurons in the} absence and presence of SCs

To delineate the elements that control the distribution and diffusional rate of $\mathrm{NaCh}$ during differentiation of the myelinated axon, we used a myelination-competent culture system of sensory neurons and SCs to carry out the FPR measurements. Compared to intact PNS, the locus and extent of neuronal-glial cell interactions are more easily identified and can be continuously monitored in this culture system and the cell-cell interactions can be controlled at specific developmental stages by the appropriate selection of culture conditions and treatments (Eldridge et al., 1989). In addition, the cultures are accessible and permit testing of specific inhibitors or effectors of $\mathrm{NaCh}$ distribution and mobility.

To ascertain the degree of axonal-SC interaction and maturation of axons and SCs during development, DRG and SC cultures used for these studies were examined both morphologically and for the expression of cell surface molecules (Fig. 1). In pure DRG cultures, which were prepared by treating cells with 5-fluoro- 2 '-deoxyuridine to eliminate proliferating fibroblasts and SCs, all SCs were removed within $10 \mathrm{~d}$, leaving a network of bare axons (Fig. 1A). In these DRGs small axons grow out from cell bodies within a day and within 2 or $3 \mathrm{~d}$ axons begin to fasciculate, a stage that coincides with the expression of NCAM (Seilheimer and Schachner, 1988). When SCs are added back to DRG cultures, the rapidly proliferating and mobile SCs contact both single axons and bundles within $2 \mathrm{~d}$ (Fig. $1 B$ ). SCs at this initial stage are distinguished by a more rounded appearance and do not contact axons tightly. Longitudinal and cross-sectional electron micrographs of 1-weekold cocultures show that a single SC extends amorphous processes and can contact several axons. In some fields these SC processes appear to elongate along the axon surface as well as extend into the axon bundle. As shown (Moos et al., 1988; Seilheimer and Schachner, 1988; Linnemann and Bock, 1989; Wood et al., 1990), these early cell-cell interactions established in the first week involve the expression of cell adhesion molecules such as NCAM and L1 that mediate axon-SC membrane adhesion and elongation of SC processes on axons, respectively.

At 3 weeks axons in pure DRG cultures bundle, although many axons remained as single axons (Fig. 1C), and apart from a more extensive axonal network, these axons do not appear significantly different than those at 1 week. In DRG-SC cocul- 

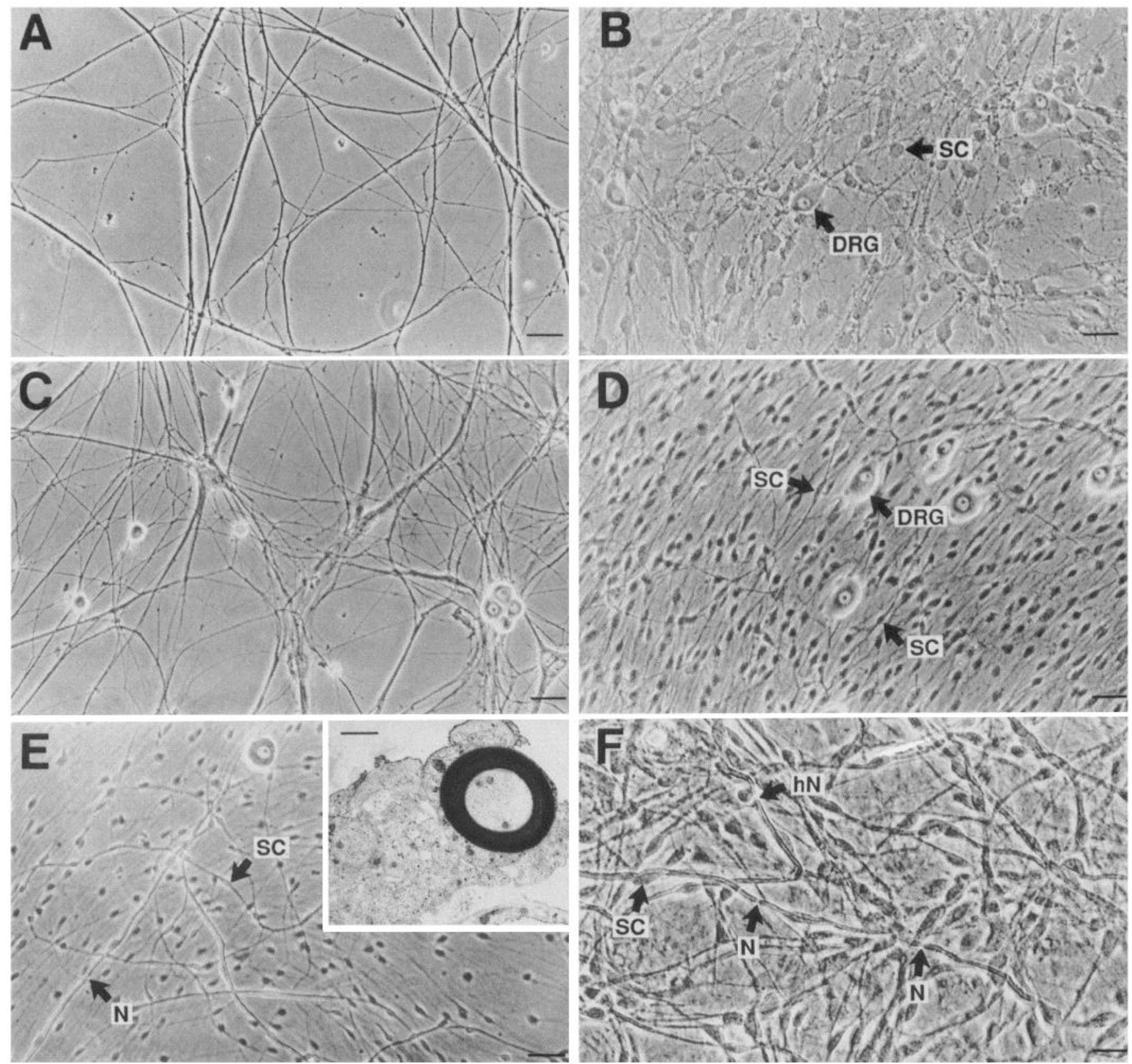

Figure 1. Characteristics of DRGs used for photobleaching studies. DRGs were cultured in the absence $(A, C)$ or presence $(B, D)$ of SCs at 1 week $(A, C), 3$ weeks $(C, D)$, and after myelination $(E, F)(N$, node; $h N$, heminode). Phase micrographs were obtained from living cultures. The inset to $E$ is an electron micrograph cross section of the myelinated cultures. Scale bars: $A-E, 25 \mu \mathrm{m} ;$ inset, $0.5 \mu \mathrm{m}$.

tures, at 3 weeks SCs contact axons much more intimately and tightly (Fig. 1D). SCs tightly adhere to axons, elongate along single axons, and assume a more flattened and extended morphology spreading along the axonal membrane. Electron microscopy of these cultures shows that SCs envelop axons and elongate their cytoplasmic extensions further along the axon, and that single axons are selectively wrapped by SC cytoplasm. In addition, there is a substantial reduction in the gap between axon and SC membranes compared to that at 1 week. However, no SCs appeared to encircle axons more than once at this stage. When this degree of Schwann cell-axon contact had developed, myelination was induced with the addition of ascorbic acid.

Figure 2. Distribution of NaChs and Thy 1.1 on 1-week-old DRGs in the absence $(A, B)$ or presence $(C, D)$ of SCs. Cells were double labeled with a mouse monoclonal anti-Thy 1.1 (1:40 dilution) $(B, D)$ and with an anti-rabbit NaCh-specific polyclonal antibody (1:100 dilution), 7493 ( $A$, $C)$. NaChs and Thy 1.1 were visualized by rhodamine- and fluorescein-conjugated secondary antibodies, respectively. Fluorescence images were obtained through a $63 \times, 1.3 \mathrm{NA}$ objective on a Zeiss Axovert microscope and images were captured in digital format through a $512 \times 512 \mathrm{CCD}$ camera interfaced to a Perceptics Image processor. Micrographs were printed on a Sony color video printer. Scale bar, $20 \mu \mathrm{m}$. 


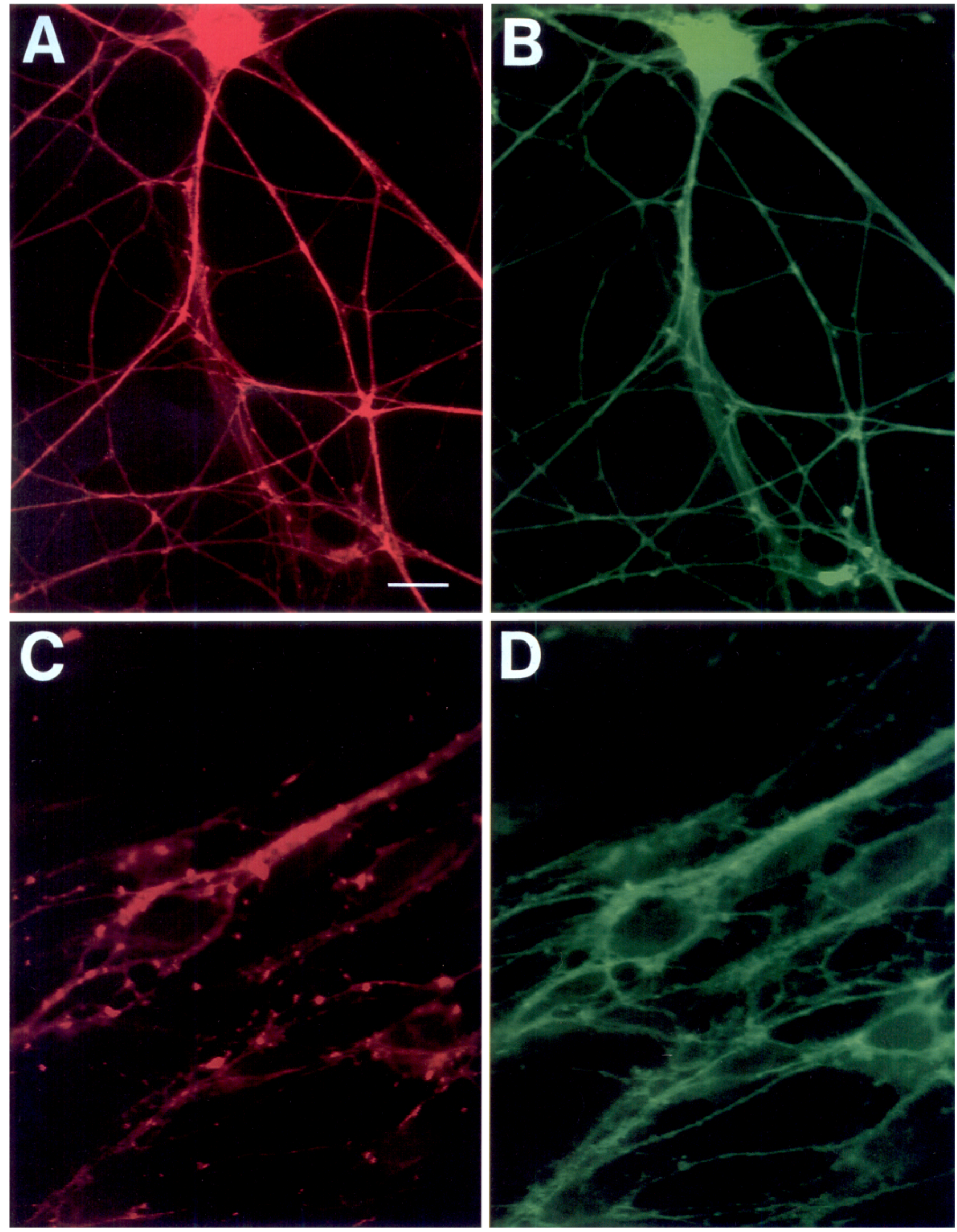



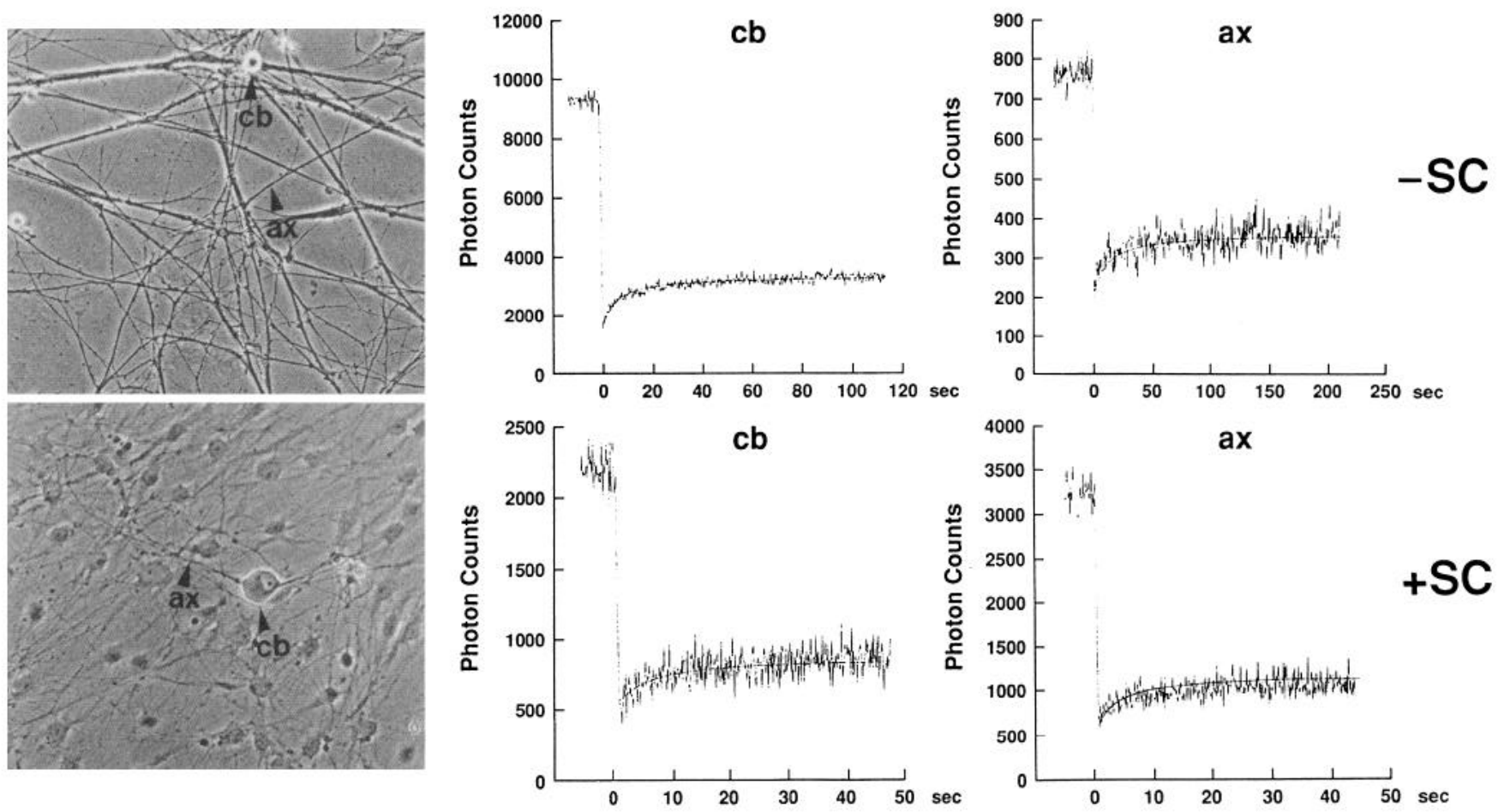

Figure 3. Representative FPR curves of TmRhd-Tityus $\gamma$-labeled NaChs in 1-week-old cultures of DRG in the absence ( $-S C)$ or in the presence $(+S C)$ of SCs. The FPR curves were obtained at the cell body $(c b)$ and axon $(a x)$. Locations are indicated. Cells were labeled with $4 \mathrm{~nm}$ TmRhdTityus $\gamma$ and then mobility measurements were carried out using a $63 \times, 1.4$ NA water immersion objective $(0.45 \mu \mathrm{m}$ beam radius). Photon counts were measured within $50 \mathrm{msec}$ dwell time. Nonspecific labeling measured in the presence of $1 \mu \mathrm{M}$ unlabeled Tityus $\gamma$ toxin was $<10 \%$ of the experimental fluorescence. In the FPR experiments where SCs accompanied DRGs, the fluorescence on SC bodies was 50-100 photon counts.

Under phase or bright-field optics, compact myelin segments appeared as thicker birefringent structures (Fig. $1 E$ ), which was confirmed by electron microscopy (inset, Fig. $1 E$ ). The average diameter of these myelinated axons is $\sim 1.4 \mu \mathrm{m}$. In these cultures, SC bodies can still be discerned (SC) and both nodes (N) and heminodes $(\mathrm{hN})$ are found (Fig. $1 E, F)$. In our cultures we found more heminodes than nodes; this is reasonable because the formation of a node requires two adjacent SCs on an axon segment. The compact myelin formed by SCs around selected axons and the myelinated axons in these cultures appear indistinguishable from those found in vivo.

For the lateral mobility studies here, 1-week-old cultures were used because axons are sufficiently well developed for FPR, and SCs have initiated contact. The extensive contact with axons, even though they have not yet established the one-to-one relationship required for myelination (Webster et al., 1973; Eldridge et al., 1989), had additional effects on $\mathrm{NaCh}$ mobility. At later developmental stages, 3-week-old and myelinated cultures were also examined.

\section{Distribution of NaChs and Thy 1.1 on DRG axons in the presence and absence of SCs}

To obtain a view of the distribution of the $\mathrm{NaCh}$ in these cultures and to provide insights into the origin of the $\mathrm{NaChs}$, DRG-SC cocultures or pure DRGs were labeled with an $\mathrm{NaCh}$-specific antibody, 7493, and anti-Thy 1.1 antibody, which is reported to stain neurons (Fields et al., 1978) (Fig. 2), and digital images were acquired. $\mathrm{NaChs}$ remain homogeneously distributed on the axon in the absence of SCs (Fig. $2 A$ ) but within 1 week $\mathrm{NaChs}$ are clustered on axons in the presence of SCs (Fig. 2C). The number of $\mathrm{NaCh}$ clusters is related to the density of SCs.
In areas of the culture where there are more SCs, $\mathrm{NaCh}$ clusters were more abundant. Although SCs have NaChs (Shrager et al., 1985), the anti-NaCh antibody 7493 stains SCs very weakly compared to DRGs $(<10 \%)$. Therefore, axonal staining can be distinguished from SC bodies or processes (Fig. 2C).

This clustering and change in the distribution of $\mathrm{NaChs}$ on the axon membrane by SC is not a general feature of all axonal membrane proteins, because the same cultures labeled with neural-specific anti-Thy 1.1 antibody showed that in contrast to $\mathrm{NaChs,} \mathrm{Thy} 1.1$ is distributed homogeneously along the axon with no discernible differences in the staining patterns or in the fluorescence intensities between regions on the axon (Fig. $2 B, D$ ). Both sConA receptors and NCAM also remain homogeneously distributed in the presence of SCs (not shown). Therefore, despite the intimate contact between axon and SC membrane, the $\mathrm{SC}$ does not have a general role in organizing all glycoproteins on the axon membrane. These results suggest that $\mathrm{NaCh}$ clustering on axons is an $\mathrm{NaCh}$-specific property induced by SCs.

Because the images were obtained in digital format within the linear range of the CCD camera, the average fluorescence intensities per pixel corresponding to the relative density of $\mathrm{NaChs}$ could be measured at noncontact and at clustered sites and compared in the same image. At noncontact sites, over a 15$20 \mu \mathrm{m}$ distance, the average $\mathrm{NaCh}$ fluorescence intensity per pixel was $1670 \pm 323$, which compares with $6614 \pm 982$ at clusters and $1770 \pm 528$ in regions of the axon between clusters $(\sim 14 \mu \mathrm{m})$.

As contact between axon and SC becomes more intimate during the next 2-3 weeks in the maturation of these cultures, although the number of $\mathrm{NaCh}$ clusters decreased (data not shown), the relative intensity differences between noncontact 


\section{A. $\mathrm{NaCh}$}
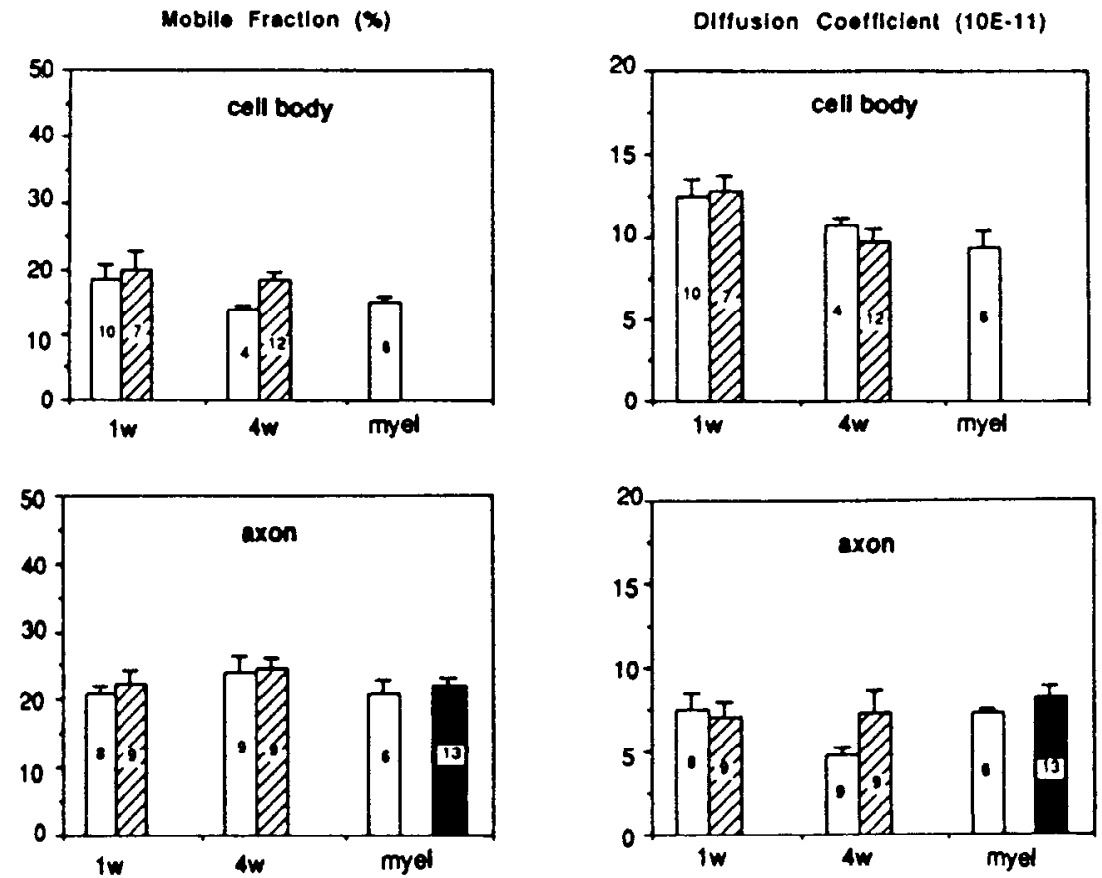

\section{B. Glycoprotein}

Moblie fraction ( $(x)$

Diffusion Coofficient (10E-11)
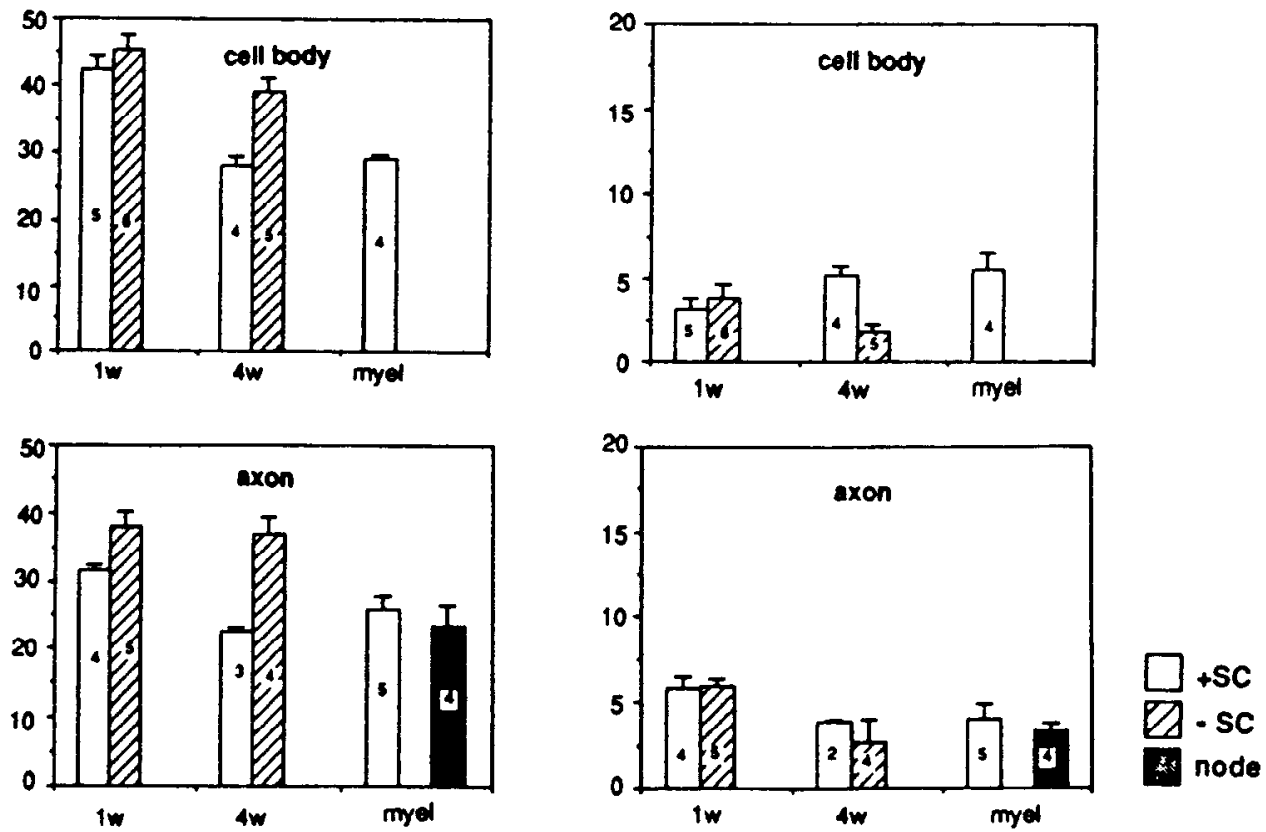

Figure 4. Comparison of the mobility of NaChs $(A)$ and sConA receptors $(B)$ on DRGs in the presence $(+S C)$ and the absence $(-S C)$ of SCs during development. Cells at 1 week, 4 weeks, and after myelination were labeled with either TmRhd-Tityus $\gamma$ or TmRhdsConA. The fluorescence recovery curves were obtained as in Figure 3 and mobile fractions and diffusion coefficients were determined by curve-fitting procedures (Axelrod, 1983). The number of measurements is shown in each bar; error bars represent SEM.

and contact/clustered sites remained the same. Electron micrographs of these cultures indicate that this stage coincides with the withdrawal of the SC membrane with the multiple axons that is established early on, and with a stage where the SC interacts with fewer axons, ultimately establishing a one-to-one relationship with a selected axon.

\section{Lateral mobility of $\mathrm{NaCh}$ during development}

Although immunocytochemistry and imaging provide a useful view of the distribution of $\mathrm{NaChs}$ and the ultrastructural features that might participate in the segregation of $\mathrm{NaChs}$, how is this topography controlled and maintained by SCs? 


\section{A. NaChs}
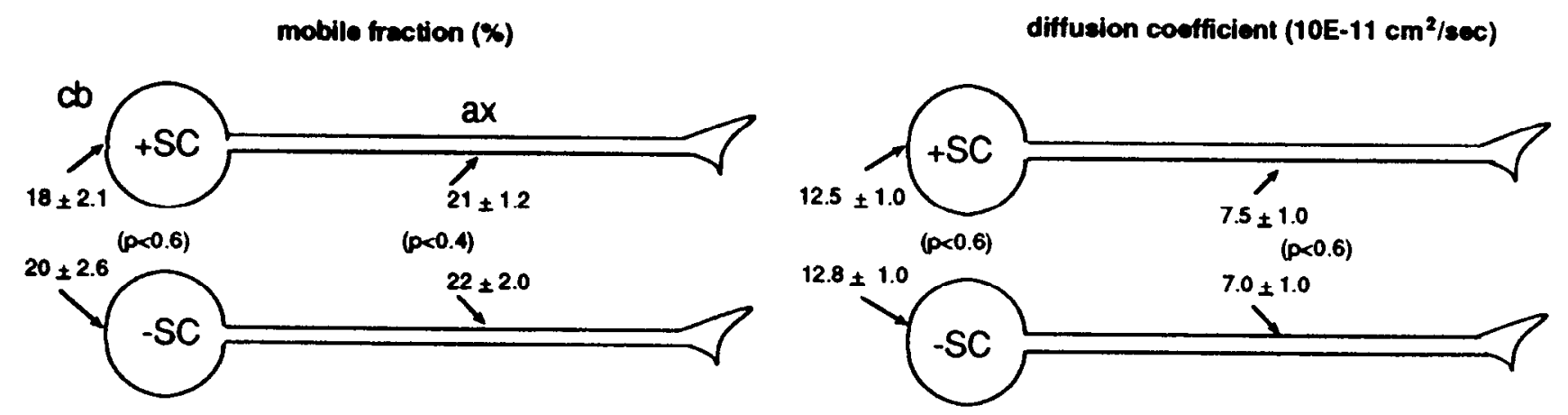

\section{B. glycoproteins}
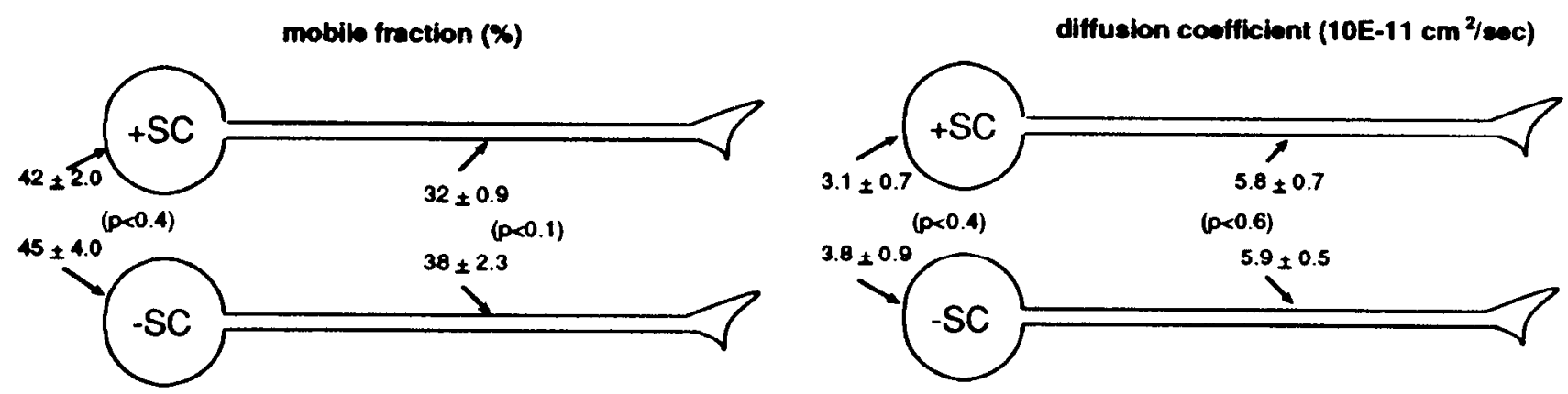

Figure 5. Statistical comparison of mobilities of $\mathrm{NaChs}(A)$ and glycoproteins $(B)$ in the presence or absence of SCs. Mobile fractions and diffusion coefficients at cell bodies $(c b)$ and axons $(a x)$ in 1-week-old cultures were compared. Student's $t$ tests were used for statistical analysis of two values above and below $p$ values.

We have used FPR to examine the role and magnitude of intracellular and/or extracellular constraints to $\mathrm{NaCh}$ diffusion and the mechanisms by which $\mathrm{NaCh}$ are organized, segregated, and confined to specialized regions of the axon by SCs. In order to investigate whether SCs modulate the axonal distribution of $\mathrm{NaChs}$ by regulating $\mathrm{NaCh}$ mobility on the axon membrane, we measured the lateral mobility of fluorescently labeled $\mathrm{NaChs}$ in cultured DRGs in the presence and the absence of SCs, as in Figure 3.

Even in pure neurons without SCs, we were quite surprised to find that in all regions of the neuron $>80 \%$ of NaChs were immobile on the time scale of the FPR measurement $\left(<10^{-12}\right.$ $\mathrm{cm}^{2} / \mathrm{sec}$ ). There was, however, a small mobile fraction $(20 \%)$ of $\mathrm{NaChs}$ on axons, axon hillocks (not shown), and cell bodies with diffusion coefficients of $5-13 \times 10^{-11} \mathrm{~cm}^{2} / \mathrm{sec}$ (Fig. $4 A$ ). Measurement of $\mathrm{NaCh}$ mobility at $\mathrm{NaCh}$ clusters or at uniform sites on the axon showed no discernible differences. Statistical analyses using Student's $t$ test show that NaCh mobilities do not change in the presence of SCs (Fig. $5 A$ ).

Because there are additional changes in $\mathrm{NaCh}$ distribution accompanying axon-SC maturation, we measured $\mathrm{NaCh}$ mobility in more developed cultures ( $3-4$ weeks), where the number of $\mathrm{NaCh}$ clusters had decreased despite the tighter contact between axons and SCs. Even in these cultures, there were no discernible differences between parallel cultures of neurons and neuron-SC cocultures in regions and at times where electron micrographs show more intimate contact with axons and when single axons are selected to become myelinated (Fig. $4 A$ ). Thus, at least at the level of the resolution and in the microdomains sampled by FPR, there appear to be no maturational effects of $\mathrm{SC}$ contact and axon segregation on $\mathrm{NaCh}$ mobility. Even after compact myelin is formed, both the mobile fraction and diffusion coefficients of NaChs are comparable to those measured at 1 week (Fig. $4 A$ ).

To examine whether these characteristics were similar for all axonal membrane proteins, we measured the mobility of glycoproteins labeled with rhodamine-sConA under the same conditions and at the same developmental stages. In contrast to $\mathrm{NaChs}$, a large fraction of glycoproteins is mobile and the mobile fraction decreases in the presence of SCs (Fig. $4 B$ ). As shown in Figure $5 B$, the mobile fraction of glycoproteins is altered with $\mathrm{SCs}$ in all regions of the axon even in one-week-old cultures. The decreased mobility could be due to the interactions between glycoproteins and cell adhesion molecules and/or extracellular matrix proteins (Jacobson et al., 1987), which are secreted by SCs (Bunge et al., 1986; Eldridge et al., 1989). Measurement of glycoprotein mobility in 3-4-week-old or myelinated cultures showed a significant decrease in the fraction of glycoproteins that were mobile (23-29\%; Fig. 4B), particularly in the presence of SCs. The decrease in mobile fraction of glycoproteins during development could have its origins in the increased membrane density of membrane proteins (Jacobson et al., 1987) or from the closer apposition of axon and Schwann cell membrane surfaces (Eldridge et al., 1989), which somehow selectively excludes 
Table 1. Effect of colchicine and cytochalasin $B$ on mobility of NaChs

\begin{tabular}{lccc} 
& No treatment & Colchicine & Cytochalasin B \\
\hline A. Mobile fraction (\%) & & \\
Cell body & $19.5 \pm 2.6^{a}$ & $27 \pm 2.0$ & $25 \pm 0.9$ \\
Axon hillock & $25.5 \pm 2.8$ & $25 \pm 1.6$ & $19.5 \pm 2.5$ \\
Axon & $22.3 \pm 2.0$ & $26 \pm 1.0$ & $18.5 \pm 0.8$ \\
B. Diffusion coefficient $\left(10 \mathrm{E}-11 \mathrm{~cm}^{2} / \mathrm{sec}\right)$ \\
$\begin{array}{l}\text { Cell body } \\
\text { Axon hillock }\end{array}$ & $12.8 \pm 1.0$ & $18.1 \pm 2.6$ & $8.6 \pm 2.3$ \\
Axon & $7.5 \pm 1.2$ & $17.1 \pm 3.0$ & $13.4 \pm 2.5$ \\
\hline
\end{tabular}

${ }^{a}$ Standard mean error.

an effect on the mobility of $\mathrm{NaCh}$. These results indicate that the small mobile fraction of $\mathrm{NaChs}$ that remains independent of SC contact during development is a property that has specificity for the $\mathrm{NaCh}$ protein.

Because SCs did not appear to affect $\mathrm{NaCh}$ mobility, we explored whether the immobility of $\mathrm{NaChs}$ arose from elements that were expressed in the axon very early in differentiation of the axon. In particular, in view of our previous work implicating the cytoskeleton (Angelides et al., 1988; Srinivasan et al., 1988), we asked whether the cytoskeleton served as a primary force that constrained $\mathrm{NaCh}$ mobility on the axon membrane. First, to test whether microtubules or actin filaments were directly involved in immobilizing $\mathrm{NaChs}$ in bare axons, neurons were treated with $5 \mu \mathrm{g} / \mathrm{ml}$ colchicine or $5 \mu \mathrm{g} / \mathrm{ml}$ cytochalasin B and the lateral mobility of $\mathrm{NaCh}$ was measured. Table 1 shows that neither colchicine nor cytochalasin $\mathrm{B}$ affects the mobile fraction of channels, although both agents slightly increase the diffusion coefficients, approximately 1.6-2.8-fold, on axons and at axon hillocks. The increase in the rate of lateral mobility in these regions with cytochalasin and colchicine was not an $\mathrm{NaCh}$-specific feature because sConA receptors responded similarly to these agents. Therefore, neither microtubules nor actin filaments appear directly responsible for creating the immobile fraction of $\mathrm{NaChs}$. If the cytoskeleton is involved in immobilizing $\mathrm{NaChs,}$ the results of these experiments suggest that it is above the level of actin filaments or microtubules (Srinivasan et al., 1988; Wood and Angclidcs, 1989).

These experiments, however, cannot unequivocally discriminate whether $\mathrm{NaCh}$ immobility is a result of a direct linkage between $\mathrm{NaChs}$ and the cytoskeleton or whether the restriction is by a corral-like barrier imposed by the underlying matrix. Bleaching of $\mathrm{NaChs}$ in a $0.45 \mu \mathrm{m}$ spot, greater than the dimension of the barrier, would also appear immobile (Edidin and Stroynowski, 1991). To ask whether NaChs were confined by a cytoskeletal barrier or directly linked, we determined the fraction of $\mathrm{NaChs}$ associated with the detergent-insoluble cytoskeleton by extraction with Triton X-100. Treatment with $0.5 \%$ Triton X-100 removes membrane lipids and soluble proteins, but leaves those proteins linked to the cytoskeleton (Marsh and Letourneau, 1984). In cell bodies and axons, $22 \%$ and $17 \%$ of channels, respectively, were extracted (Table 2). Therefore, it appears that approximately $80 \%$ of $\mathrm{NaChs}$ are likely to be associated with the cytoskeleton by a direct linkage. Ankyrin has been suggested as the cytoskeleton linker (Angelides et al., 1988; Wood and Angelides, 1989; Srinivasan et al., 1992). In addition, immunocytochemistry of these cultures shows the appearance
Table 2. Fraction of NaChs extracted by $0.5 \%$ Triton $\mathrm{X}-100$

\begin{tabular}{lcll} 
& - Triton X-100 & +Triton X-100 & $\begin{array}{l}\% \text { extrac- } \\
\text { tion }\end{array}$ \\
\hline Cell body & $8560 \pm 688^{a}$ & $6666 \pm 866$ & 22 \\
Axon hillock & $2738 \pm 246$ & ND $^{b}$ & ND \\
Axon & $731 \pm 60$ & $606 \pm 33$ & 17 \\
\hline
\end{tabular}

${ }^{a}$ Standard mean error.

${ }^{h}$ Not determined.

of detectable levels of spectrin and ankyrin within a day even without SCs (Joe and Angelides, 1992). This would be consistent with the hypothesis that the axon itself provides constraints on $\mathrm{NaChs}$ that limit diffusion $\mathrm{NaChs}$ in the membrane.

\section{Discussion}

There has been considerable discussion as to what role glial cells play in organizing $\mathrm{NaChs}$ on the axon membrane (Smith et al., 1982; Le Beau et al., 1987; Rosenbluth, 1988; Bigbee and Foster, 1989). Several studies have suggested that specialization of the node and the highly restricted distribution of NaChs is determined by glial-axonal contact (Rosenbluth, 1988; Bigbee and Foster, 1989), while other studies have suggested that nodal specializations and clustering of $\mathrm{NaChs}$ develop independently of ensheathing cell contact (Smith et al., 1982; Le Beau et al., 1987).

Recently, we have shown that segregation of $\mathrm{NaChs}$ on axons is highly dependent on interactions with active SCs and that continuing axon-glial interactions are necessary to organize $\mathrm{NaCh}$ distribution during differentiation of the myelinated axon (Joe and Angelides, 1992). Specifically, in the absence of SCs, NaChs are homogeneously distributed along axons, but when SCs accompany or are reintroduced into neuronal cultures, $\mathrm{NaCh}$ distribution on the axon dramatically changes from homogeneous to clustered. The change in axonal distribution requires a component of the SC membrane that is expressed upon axon contact and specific for NaChs since other membrane proteins such as Thy 1.1, NCAM, and sConA receptors remain homogeneously distributed. Furthermore, these changes in $\mathrm{NaCh}$ distribution are not accompanied by changes in the distribution of ankyrin or spectrin, which remain homogencously distributed, even though at fully differentiated nodes of Ranvier ankyrin colocalizes with NaChs (Kordeli et al., 1990).

In this work, we have measured the mobility of $\mathrm{NaChs}$ to gain insight into whether homogeneously distributed $\mathrm{NaChs}$ could redistribute and cluster at specific sites on the axon determined by SC-axon contact by diffusion within the axon membrane. Previous light and electron micrographs have shown the intimate interactions that develop between axon and SC membranes where the SC membrane is closely apposed to and elongates along the axon surface, constantly maintaining its close association with the axon surface (Clark and Bunge, 1989). It is clear that there is a programmed expression of specific adhesion molecules on axons and SCs during this developmental sequence that mediates the axon-SC interaction (Linnemann and Bock, 1989; Wood et al., 1990). During the early stages, when NCAM is cxpressed, SCs appear to establish contact with many axons and $\mathrm{NaCh}$ clusters are abundant. We have observed that the density and number of $\mathrm{NaCh}$ clusters, however, decrease as the $\mathrm{SC}$ reaches the stage where it commits to a one-to-one 
relationship with the axon (E-h Joe and K. J. Angelides, unpublished observations).

Given the extensive interactions between these cells, we asked whether (1) the mobility of $\mathrm{NaCh}$ and axonal membrane glycoproteins was modified by SCs, (2) NaCh clusters could originate from a redistribution of preexisting $\mathrm{NaChs}$, and (3) SCs provided constraint or a barrier whereby $\mathrm{NaCh}$ clusters were maintained or segregated on the axon.

Surprisingly, the results show that even without SCs NaChs in axons are largely immobile $(80 \%)$ and that the mobility of $\mathrm{NaChs}$ is not modified with SC contact. Moreover, the results suggest that even in the absence of SCs intracellular constraints expressed by the axon itself provide a selective constraint on $\mathrm{NaCh}$ movement on the axon membrane. This restrictive force is likely provided by the cytoskeleton since approximately $80 \%$ of the $\mathrm{NaChs}$ are associated with the detergent-insoluble cytoskeleton, a fraction of $\mathrm{NaChs}$ that corresponds to the immobile fraction of NaChs determined by FPR. Neither microtubules nor microfilaments directly regulate $\mathrm{NaCh}$ mobility since colchicine and cytochalasin do not alter the mobile fraction of $\mathrm{NaChs}$. These observations are consistent with biochemical evidence showing that $\mathrm{NaChs}$ are directly linked to ankyrin and the spectrin-based cytoskeleton (Srinivasan et al., 1988) and that the association of ankyrin and spectrin with $\mathrm{NaChs}$ controls $\mathrm{NaCh}$ mobility (Wood and Angelides, 1989). Taken together, the FPR and biochemical experiments suggest that even early on in development direct linkages established between $\mathrm{NaChs}$ and the ankyrin/spectrin-based cytoskeleton, rather than barriers formed by the subaxolemmal cytoskeletal meshwork, are responsible for immobilizing NaChs. However, the small fraction of mobile $\mathrm{NaChs}$ could be regulated by the spectrin-actin (Sheetz et al., 1980) and/or spectrin-microtubule network because the diffusion coefficient of mobile $\mathrm{NaChs}$ is increased slightly in the presence of either cytochalasin or colchicine. Spectrin and associated proteins may form corral-like barriers (Edidin et al., 1991) where mobile $\mathrm{NaChs}$ move within a spectrin barrier and rarely cross the boundary. Depolymerization of actin or microtubules after cytochalasin or colchicine treatment weakens the spectrin barrier, resulting in increased movement of mobile $\mathrm{NaChs}$. We conclude that even without SCs the subaxolemmal cytoskeleton provides a mechanism by which $\mathrm{NaCh}$ mobility is restricted. The intracellular constraints appear strong enough that extensive interactions on the external face of the axon and the remodeling of other axon membrane proteins through $\mathrm{SC}$ contact do not influence or alter $\mathrm{NaCh}$ mobility.

In contrast to our previous work on the distribution and mobility of $\mathrm{NaChs}$ on spinal cord motoneurons, which are also myelinated, we observed that the mobility of NaChs on sensory/ DRG neurons did not differ significantly in different regions of the neurons. In spinal cord neurons $\mathrm{NaChs}$ are diffusely distributed at low density on the cell body, but segregated at high density at the axon hillock. In addition, on spinal cord motoneurons, $\mathrm{NaChs}$ are freely mobile on the cell body but immobilized at the axon hillock. These differences between sensory/ DRG neurons and spinal cord motoneurons could be due to the $\mathrm{NaCh}$ subtypes expressed by these different neurons (Roy and Narahashi, 1992; Campbell, in press). The intracellular machinery that localizes these NaChs to different parts of the neuron and the differences in density and localization may reflect functional differences in the manner by which the action potential is generated by these fibers (Kandel et al., 1991).

Given that most NaChs are immobilized on the FPR time scale and linked to the axonal cytoskeleton, how does SC contact modify $\mathrm{NaCh}$ distribution and how are the NaCh clusters formed? One possibility is that $20 \%$ of the $\mathrm{NaChs}$ that are mobile and diffuse are trapped at sites formed by the SCs in a manner similar to the aggregation of $\mathrm{ACh}$ receptors (AChRs) at the developing neuromuscular junction of Xenopus (Poo and Young, 1990). The clustering and entrapment, however, are selective since Thy 1.1 , general glycoproteins, and NCAM, which are laterally mobile on the axon surface, do not accumulate with $\mathrm{NaChs}$ at these sites.

If we consider that the existing homogeneously distributed and mobile $\mathrm{NaChs}$ measured by FPR are redistributed to clusters upon SC contact, can the preexisting and homogeneously distributed NaChs reach these sites? Analysis of the rates of lateral diffusion of $\mathrm{NaChs}$ shows that $\mathrm{NaCh}$ movement in the membrane is indeed rapid enough to account for the entrapment of the channels at or near contact sites if the sites of contact serve as an ideal sink or a barrier for channel diffusion. In DRG$\mathrm{SC}$ cocultures, $\mathrm{NaCh}$ clusters appear approximately $5 \mathrm{~d}$ after reseeding cultures with SCs (Joe and Angelides, 1992). On single axons we have measured that the average distance between $\mathrm{NaCh}$ clusters is approximately $14 \mu \mathrm{m}$ at this stage. $\mathrm{An} \mathrm{NaCh}$ in random motion with a diffusion coefficient of $\sim 10^{-10} \mathrm{~cm}^{2} /$ sec would take approximately $1.5 \mathrm{hr}$ to diffuse a root-meansquare distance of $14 \mu \mathrm{m}\left(x^{2}=4 D t\right.$, where $x$ is the distance the molecules move, $D$ is a diffusion coefficient, and $t$ is time). Given these rates it would seem that the rate of lateral diffusion for even $20 \%$ of the channels could be consistent with their appearance at cluster sites and would be rapid enough to reach clustering sites even within a day.

Even if the rate is compatible with surface diffusion, trapping, or a selective barrier created by SCs, are there enough $\mathrm{NaChs}$ on these axons that redistributed $\mathrm{NaChs}$ could reach the densitics of $\mathrm{NaChs}$ at cluster sitcs? Mcasurement of the fluorescence intensity, corresponding to the relative density of $\mathrm{NaChs}$, revealed that $\mathrm{NaCh}$ intensity at clusters is about four times higher than that around clusters. If $20 \%$ of the $\mathrm{NaChs}$ in a $14 \mu \mathrm{m}$ homogeneous region of the axon were segregated into a $1 \mu \mathrm{m}$ cluster site, the density of clusters would be four times higher than adjacent membrane. Although we have not excluded the possibility of local incorporation at the cluster site together with a degradation of $\mathrm{NaChs}$ in regions between clusters, our results are consistent with the simplest hypothesis that accumulation could result from a redistribution of the small population of preexisting and mobile $\mathrm{NaChs}$.

What could be the molecular basis for $\mathrm{NaCh}$ clustering? First of all, the clustering sites must be formed in the presence of SCs and show selectivity. Like that suggested for the clustering of $\mathrm{AChRs}$ at the developing neuromuscular junction (Poo and Young, 1990) and lateral migration and recruitment to these sites by agrin (Godfrey et al., 1984), accumulation and trapping of $\mathrm{NaChs}$ may arise by binding to specific ligands on the apposing $\mathrm{SC}$ membrane, while other axon membrane components that do not have this specificity in binding are excluded from these contact regions. Several reports have shown that cell-cell contact and extracellular interactions may be an important mechanism by which membrane protein distribution is modulated. Chow and Poo (1982) found that in embryonic muscle cells, cell surface lectin receptors underwent rapid redistribution (even at sites remote from the contact sites) that was dependent on the degree of cell contact. Furthermore, there is specificity in the affinity for certain lectins to redistribute at these contact 
sites. These studies suggest that specific molecular interactions between components of the contacting surfaces result in redistribution of preexisting, rapidly diffusing surface receptors (Chow and $\mathrm{Poo}, 1982$ ). The $\mathrm{NaCh}$ protein is an unusually high glycosylated protein (30\% carbohydrate by weight) (Schmidt and Catterall, 1987; James and Agnew, 1989). Therefore, it is possible that the SC membrane may contain lectin-like molecules specific for polysialic acid or $N$-acetyl- $\beta$-D-glucosaminyl oligomers, which are structural features of the $\mathrm{NaCh}$ protein (Miller et al., 1983; James and Agnew, 1989) and could serve to trap $\mathrm{NaChs}$. Alternatively, it is possible that $\mathrm{NaChs}$ are excluded from specific regions of the axon where $\mathrm{SC}$ and axon membranes interact.

How are $\mathrm{NaCh}$ clusters produced? It is known that the axon and SCs undergo a programmed expression of adhesion molecules on their surfaces that are important for each developmental stage during myelination (Wood et al., 1990). Such selective adhesion plays an important role in the morphogenesis of the myelinated axon (Rieger et al., 1986). The accumulation of axonal components at sites of SC contact by the binding of axonal membrane receptors with specific ligands on the apposing SC surface could serve as a mechanism for enhancing selective adhesion of the two surfaces and for initiating $\mathrm{NaCh}$ cluster formation. Alternatively, localization and immobilization of adhesion molecules targeted to specific regions of the $\mathrm{SC}$ membrane could regulate axonal $\mathrm{NaCh}$ distribution by the interaction directly with $\mathrm{NaChs}$, an axonal component associated with $\mathrm{NaChs}$ (Pollerberg et al., 1987; Persohn et al., 1989), or by creating a selective barrier to $\mathrm{NaCh}$ movement into the developing internode. A third possibility is that a specific component in the SC membrane that is expressed only with axonal contact and localized at the site of axonal contact provides an interaction or barrier to mobile $\mathrm{NaChs}$ and is sufficient to entrap and seed or exclude the first $\mathrm{NaCh}$ aggregates before full $\mathrm{SC}$ envelopment occurs. Thus, membrane components on the SC membrane, themselves polarized and immobilized, could provide the localization signals and sites where mobile and diffusing $\mathrm{NaChs}$ become entrapped or excluded.

Finally, despite the consistency of our data with a diffusion trap or selective barrier for $\mathrm{NaCh}$ segregation, we have not ruled out two other possibilities. First, newly synthesized $\mathrm{NaChs}$ could be actively inserted at sites of SC contact that have higher affinity for vesicle fusion. Second, NaChs are inserted into the membrane randomly but turned over more rapidly in regions ensheathed by SCs due to signals transduced only in those axonal regions overlaid by SCs. However, in mobility studies, we did not observe any differences in the mobility of $\mathrm{NaCh}$ in regions between clustering sites overlaid by SCs along axons that would likely signal the prerequisite disruption of the interaction between NaChs and the SC membrane and/or NaChs and the cytoskeleton. Moreover, from image analysis, we found that the intensity of $\mathrm{NaCh}$ staining at clusters is about four times higher than that at axons without SC contact. Therefore, $\mathrm{NaCh}$ clusters should be formed by insertion of $\mathrm{NaCh}$ at clustering sites rather than eliminating $\mathrm{NaChs}$ from nonclustering sites.

Evidence from experiments performed in cultured chick myotubes shows that $\mathrm{AChR}$ clusters are formed by active insertion of new receptors after innervation (Dubinsky et al., 1989). If NaChs were axonally transported in the slow component [0.1$4 \mathrm{~mm} /$ day (Vallee and Bloom, 1991)], sorting and accumulation at distal sites could be accomplished and consistent with the rates of appearance of newly synthesized and inserted channels at clustered sites. In fact, we have observed in micrographs of cultured DRGs, with or without SCs, axon varicosities often stained with $\mathrm{NaCh}$ and ankyrin antibodies. Evidence has shown that the varicosities are anterogradely transported membranous organelles associated with kinesin (Hollenbeck and Bray, 1987; Pfister et al., 1989; Hirokawa et al., 1991). These observations provide support for the intriguing idea that these vesicles contain $\mathrm{NaChs}$ and ankyrin en route to their assembly cluster sites.

In conclusion, we have observed that SCs do not alter the mobility of $\mathrm{NaChs}$ on the axon surface yet segregation and localization of NaChs on the axon surface is highly dependent on the interactions with active SCs. The forces that are responsible for the immobilization of $\mathrm{NaChs}$ on axons in the absence of $\mathrm{SC}$. contact are likely to involve interactions with the subaxolemmal cytoskeleton, while the accumulation of $\mathrm{NaChs}$ at high density on the axon in the presence of SCs likely arises from diffusionmediated entrapment or selective exclusion of a small population of mobile NaChs. It will be important in future studies to identify the nature of the SC-axon components and interactions during development and myelination to gain further insight into the mechanisms and signals by which SCs segregate and maintain $\mathrm{NaChs}$ at discrete sites on the axon surface.

\section{References}

Angelides K, Nutter T (1983) Preparation and characterization of fluorescent scorpion toxins from Leiurus quainquestriatus as probes of the sodium channel of excitable cells. J Biol Chem 258:1194811957.

Angelides K, Elmer L, Loftus D, Elson E (1988) Distribution and lateral mobility of voltage-dependent sodium channels in neurons. $J$ Cell Biol 106:1911-1925.

Axelrod D (1983) Lateral motion of membrane proteins and biological function. J Membr Biol 75:1-10.

Barhanin J, Giglio J, Leopold P, Schmid A, Sampaio S, Lazdunski M (1982) Tityus serrulatus venom contains two classes of toxins: Tityus $\gamma$ toxin is a new tool with a very high affinity for studying the $\mathrm{Na}^{+}$ channel. J Biol Chem 257:12553-12558.

Bigbee JW, Foster RE (1989) Freeze fracture analysis of the axolemma of cultured dorsal root ganglion neurons in the absence of Schwann cells. Brain Res 494:182-186.

Black J, Waxman S, Hildebrand C (1985) Axo-glial relations in the retina-optic nerve junction of the adult rat: freeze-fracture observations on axon membrane structure. J Neurocytol 14:887-909.

Black JA, Kocsis JD, Waxman SG (1990) Ion channel organization of the myelinated fiber. Trends Neurosci 13:48-54.

Bottenstein JE, Sato GH (1979) Growth of a rat neuroblastoma cell line in serum free supplemented media. Proc Natl Acad Sci USA 76: 514-517.

Bunge R, Bunge M, Eldridge C (1986) Linkage between axonal ensheathment and basal lamina production by Schwann cells. Annu Rev Neurosci 9:305-328.

Clark M, Bunge M (1989) Cultured Schwann cells assemble normalappearing basal lamina only when they ensheathe axons. Dev Biol 133:393-404.

Chow I, Poo M (1982) Redistribution of cell surface receptors induced by cell-cell contact. J Cell Biol 95:510-518.

Cowan A, Myles D, Koppel D (1987) Lateral diffusion of the PH-20 protein on guinea pig sperm: evidence that barriers to diffusion maintain plasma membrane domains in mammalian sperm. J Cell Biol 104:917-923.

Diamond JM (1977) The epithelial junction: bridge, gate, and fence. Physiologist 20:10-18.

Dubinsky J, Loftus D, Fischbach G, Elson E (1989) Formation of acetylcholine receptor clusters in chick myotubes: migration or new insertion? J Cell Biol 109:1733-1743.

Edidin M, Stroynowski I (1991) Differences between the lateral organization of conventional and inositol phospholipid-anchored membrane proteins. A further definition of micrometer scale membrane domains. J Cell Biol 112:1143-1150.

Edidin M, Kuo S, Sheetz M (1991) Lateral movements of membrane 
glycoproteins restricted by dynamic cytoplasmic barriers. Science 254 : $1379-1382$.

Eldridge C, Bunge M, Bunge R, Wood P (1987) Differentiation of axon-related Schwann cells in vitro. I. Ascorbic acid regulates basal lamina assembly and myelin formation. J Cell Biol 105:1023-1034.

Eldridge C, Bunge M, Bunge R (1989) Differentiation of axon-related Schwann cells in vitro: II. Control of myelin formation by basal lamina. J Neurosci 9:625-638.

Ellisman M (1979) Molecular specializations of the axon membrane at nodes of Ranvier are not dependent upon myelination. J Neurocytol 8:719-735.

Elmer LW, Black JA, Waxman SG, Angelides KJ (1990) The voltagedependent sodium channel in mammalian CNS and PNS: antibody characterization and immunocytochemical localization. Brain Res 532:222-231.

Fields KL, Brocker JP, Mirsky R, Wendon LMB (1978) Cell surface markers for distinguishing different types of rat dorsal root ganglion cells in culture. Cell 14:43-51

Godfrey EW, Nitkin RM, Wallace BG, Rubin LL, McMahan UJ (1984) Components of Torpedo electric organ and muscle that cause aggregation of acetylcholine receptors on cultured muscle cells. J Cell Biol 99:615-627

Hirokawa N, Sato-Yoshitake R, Kobayashi N, Pfister K, Bloom G, Brady S (1991) Kincsin associates with anterogradely transported membranous organelles in vivo. J Cell Biol 114:295-302.

Hodgkin AL, Huxley AF (1952) A quantitative description of membrane current and its application to conduction and excitation in nerve. J Physiol (Lond) 1 17:500-544.

Hollenbeck PJ, Bray D (1987) Rapidly transported organelles containing membrane and cytoskeletal components: their relation to axonal growth. J Cell Biol 105:2827-2835.

Huxley AF, Stampfli R (1949) Evidence for saltatory conduction in peripheral myelinated nerve fibers. J Physiol (Lond) 108:315-339.

Huxley AF, Stampfi R (1951) Effect of potassium and sodium on resting and action potentials of single myelinated nerve fibers. $J$ Physiol (Lond) 112:496-508.

Jacobson K, Ishihara A, Inman R (1987) Lateral diffusion of proteins in membranes. Annu Rev Physiol 49:163-175.

James W, Agnew W (1989) a-(2-8-polysialic acid immunoreactivity in voltage-sensitive sodium channel of eel electric organ. Proc $R$ Soc Lond [Biol] 237:233-245.

Joe E, Angelides K (1992) Clustering of voltage-dependent sodium channels on axons depends on Schwann cell contact. Nature 356:333335.

Kandel E, Schwartz J, Jessell T (1991) Neural cells and behavior. In: Principles of neural science, 3d ed, pp 18-32. New York: Elsevier.

Kobayashi T, Storrie B, Simons K, Dotti CG (1992) A functional barrier to movement of lipids in polarized neurons. Nature $359: 647$ 650.

Kordeli E, Davis J, Trapp B, Bennett V (1990) An isoform of ankyrin is colocalized at the nodes of Ranvier in myelinated axons of central and peripheral nerves. J Cell Biol 110:1341-1352.

Kristol C, Sandri C, Akert K (1978) Intramembranous particles at nodes of Ranvier of the cat spinal cord: a morphometric study. Brain Res 142:391-400.

Le Beau JM, Powell HC, Ellisman H (1987) Node of Ranvier formation along fibers regenerating through silicone tube implants: a freeze-fracture and thin section electron microscopic study. J Neurocytol $16: 347-358$

I innemann D, Bock E (1989) Cell adhesion molecules in neural development. Dev Neurosci 11:149-173.

Marsh L, Letourneau C (1984) Growth of neurites without filopodial or lamelipodial activity in the presence of cytochalasin $\mathrm{B}$. $\mathrm{J}$ Cell Biol 99:2041-2047

Miller JA, Agnew WS, Levinson S (1983) Principal glycopeptide of the tetrodotoxin/saxiton binding protein from Electrophorus: isolation and partial chemical and physical characterization. Biochemistry 22:462-470.

Moos M, Tacke R, Scherer H, Teplow D, Fruh K, Schachner M (1988) Neural adhesion molecule L1 as a member of the immunoglobulin superfamily with binding domains similar to fibronectin. Nature 334 : $710-703$.

Myles D, Koppel D, Cowan A, Phelps B, Primakoff P (1987) Rearrangement of sperm surface antigens prior to fertilization. Ann $\mathrm{NY}$ Acad Sci 513:262-273.
Nigg E, Cherry R (1980) Anchorage of a band 3 population at the erythrocyte cytoplasmic membrane surface: protein rotational diffusion measurements. Proc Natl Acad Sci USA 77:4702-4706.

Persohn E, Pollerberg G, Schachner M (1989) Immunoelectron-microscopic localization of the $180 \mathrm{kD}$ component of the neural cell adhesion molecule NCAM in postsynaptic membranes. J Comp Neurol 288:92-100.

Pfister K, Wagner M, Stenoien D, Brady S, Bloom G (1989) Monoclonal antibodies to kinesin heavy and light chains stain vesicle-like structures, but not microtubules, in cultured cells. J Cell Biol 108: 1453-1453.

Pollerberg GF, Schachner M, Davoust J (1986) Surface mobilities of two molecular weight forms of the neural cell adhesion molecule N-CAM are characteristic of distinct differentiation stages. Nature 324:462-465.

Pollerberg G, Burridge K, Krebs K, Goodman S, Schachner M (1987) The $180 \mathrm{kD}$ component of the neural cell adhesion molecule NCAM is involved in cell-cell contacts and cytoskeleton-membrane interactions. Cell Tissue Res 250:227-236.

Poo M, Young S (1990) Diffusional and electrokinetic redistribution at the synapse: a physicochemical basis of synaptic competition. J Neurobiol 21:157-168.

Rieger R, Daniloff J, Pincon-Raymond M, Crossin K, Grumet M, Edelman $G$ (1986) Neuronal cell adhesion molecule and cytotactin are co-localized at the node of Ranvier. J Cell Biol 103:379-391.

Ritchie JM, Rogart RB (1977) The density of sodium channels in mammalian myelinated nerve fibers and the nature of the axonal membrane under the myelin sheath. Proc Natl Acad Sci USA 74: 211-215.

Rosenbluth J (1976) Intramembranous particle distribution at the node of Ranvier and adjacent axolemma in myelinated axons of the frog brain. J Neurocytol 5:731-745.

Rosenbluth J (1979) Aberrant axon-Schwann cell junctions in dystrophic mouse nerves. J Neurocytol 8:655-672.

Rosenbluth J (1988) Role of glial cells in the differentiation and function of myelinated axons. Int J Dev Neurosci 6:3-24.

Rosenbluth J, Blakemore W (1984) Structural specializations of chronically demyelinated spinal cord axons as seen in freeze-fracture replicas. Neurosci Lett 48:171-177.

Roy M, Narahashi T (1992) Differential properties of tetrodotoxinsensitive and tetrodotoxin-resistant sodium channels in rat dorsal root ganglion neurons. J Neurosci 12:2104-2111.

Schmidt J, Catterall W (1987) Palmitylation, sulfation, and glycosylation of the $\alpha$-subunit of the sodium channel. Role of post-translational modifications in channel assembly. $J$ Biol Chem 262:13713-13723.

Schnapp B, Peracchia C, Mugnaini E (1976) The paranodal axo-glial junction in the central nervous system studied with thin section and freeze-fracture. Neuroscience 1:181-190.

Seilheimer B, Schachner M (1988) Studies of adhesion molecules mediating interactions between cells of peripheral nervous system indicate a major role for L1 in mediating sensory neuron growth on Schwann cells in culturc. J Ccll Biol 107:341-351.

Sheetz MP, Schindler M, Koppel DE (1980) Lateral mobility of integral membrane proteins is increased in spherocytic erythrocytes. Nature 285:510-511.

Shrager P, Chiu S, Ritchie M (1985) Voltage-dependent sodium and potassium channels in mammalian cultured Schwann cells. Proc Natl Acad Sci USA 82:948-952.

Smith KJ, Bostock H, Hall SM (1982) Saltatory conduction precedes remyelination in axons demyelinated with lysophosphatidyl choline. J Neurol Sci 54:13-31.

Srinivasan Y, Elmer L, Davis J, Bennett V, Angelides K (1988) Ankyrin and spectrin associate with voltage-dependent sodium channels in brain. Nature 333:177-180.

Srinivasan Y, Lewallen M, Angelides KJ (1992) Mapping the binding site on ankyrin for the voltage-dependent sodium channel from brain. J Biol Chem 267:7483-7489.

Stya M, Axelrod D (1983) Mobility and detergent extractability of acetylcholine receptors on cultured rat myotubes: a correlation. J Cell Biol 97:48-51.

Tsuji A, Ohnishi S (1986) Restriction of the lateral motion of band 3 in the erythrocyte membrane by the cytoskeletal network: dependence on spectrin association state. Biochemistry 25:6133-6139.

Vallee R, Bloom G (1991) Mechanisms of fast and slow axonal transport. Annu Rev Neurosci 14:59-92. 
Waxman S, Foster R (1980) Development of the axon membranc during differentiation of myelinated fibers in spinal nerve roots. Proc R Soc Lond [Biol] 290:441-446.

Waxman SG, Quick DC (1978) Intra-axonal ferric ion-ferrocyanide staining of nodes of Ranvier and initial segments in central myelinated fibers. Brain Res 144:1-10.

Webster H de F, Martin J, O'Connell M (1973) The relationships between interphase Schwann cells and axons before myelination: a quantitative electron microscope study. Dev Biol 32:401-416.

Wiley-Livingston C, Ellisman M (1980) Development of axonal mem- branc spccializations defincs nodes of Ranvier and proceeds Schwann cell myelin elaboration. Dev Biol 79:334-355.

Wood J, Angelides KJ (1989) Association of ankyrin and spectrin with sodium channels control sodium channel mobility in nerve. $J$ Cell Biol 109:162a.

Wood P, Moya F, Eldridge C, Owens G, Ranscht B, Schachner M, Bunge M, Bunge R (1990) Studies of the initiation of myelination by Schwann cells. Ann NY Acad Sci 605:1-14.

Zar J (1984) Biostatistical analysis, 2d ed, pp 162-184. Princeton, NJ: Prentice Hall. 